\title{
Safety Culture and Issue in the Malaysian Manufacturing Sector
}

\author{
Danish Ali*a ${ }^{\text {, Yusri }}$ Yusof $^{\mathrm{b}}$ and Anbia Adam ${ }^{\mathrm{c}}$ \\ Faculty of Mechanical and Manufacturing Engineering, Universiti Tun Hussein Onn \\ Malaysia
}

\begin{abstract}
This paper highlights the Safety culture and issue in the Malaysian Manufacturing Sector and emphasis the high occupational accidents due to lack of safety culture and non-compliance of the requirements of Occupational Safety and Health Act 1994. The aim of this study is to review the occupational accidents occurrence in the Malaysia workplace since 2012-2016. Malaysia aimed to reduce the occupational accidents, the results show by DOSH increase that Occupational Noise Induced Hearing Loss $83.7 \%$, occupational musculoskeletal diseases, $4.4 \%$ and occupational lung diseases $2.3 \%$. But the as per the record from DOSH that in last 5 -Years, the increment in the fatal accidents by Average 26\%, Permanent Disability by Average $71 \%$ and Non-Permanent Disability by $64 \%$ are investigated only in Manufacturing Industries. The government must show their high interest on such a vulnerable employees to accomplish the above aim. This step will be helpful for planning to reduce the accidents in workplaces and it will also detect the prevention for the future accidents.
\end{abstract}

\section{Introduction}

The Occupational Safety and Health Act 1994 (OSHA 1994) [1]was made considering the way that the Factories and Machinery Act (FMA) 1967 just secured word related safety and health in the construction industries, mining and manufacturing industry, though alternate businesses were not considered. The extent of OSHA 1994 covers all people that works in public and private sectors with the exception of military forces. The Occupational Health and Safety directions force the punishment to the employers, which they present of unsafe working conditions for their employees noncompliance with the standards [2-3].

To ensure the occupational health and safety of the persons at working in danger places, the objectives of OSHA 1994 are to protect workers at the workplace, to encourage an occupational safe environment for the employee at their workplace adjusted to their physical

*Corresponding author: yusri@uthm.edu.my 
and psychological needs, and to offer the means whereby the associated occupational safety and health legislations can be gradually changed by a system of regulations and endorsed industry codes of practice.

Nowadays, work related accident became well-known as major concerned to the industries involved. This kind of problem also closely faced by the manufacturing industry's workers that involve in the different operation of handing machine and different production equipment like the use of molding machine, fabrication equipment, cranes, prime movers, and forklifts and truck that is very much associated with the issue of safety and health awareness. In an effort to promote the development of safety and healthy workplace, as it is one of the important functions between the organization and workers to conduct their daily operation in a safe and correct manner. Workers have the high level of health and safety awareness that are able to conduct their work efficiently and professionally, where it possibly might to prevent accidents that occurred at the work related. In the work environment mishap happening during the everyday operations brings about hopeless scenario. So, when accident happens, it should always reported to the health and safety officer to ensure that instant action could be taken by the organization. Encourage assessment could be led to recognize the factors that reason of accident and so in the future to prevent the accident. A worker additionally earnest to report any near miss accident or injury either supervisor or health and safety officer. This paper helps to identify potential hazards happen in different sector, special focus on manufacturing sector and also address the different occupational accident and diseases lungs, skin and muscular disorder and in the future so that avoid accident and disease for the betterment. [4-5].

This review anticipated that would raise the level of awareness towards wellbeing of health and safety needs at workplace. Furthermore employers or supervisors for most part can recognize what are the causes that play important role accident among their workers and can take the protection measures in controlling them. [6].

\section{Safety culture and Problems in the Malaysian Manufacturing}

\section{Sector}

These days, safety culture has turned into the key factor determining the association's wellbeing execution safety performance. Safety culture plays an important role to deciding the organization's success or failure. The role of safety culture also play among the others targeted organization towards outstanding safety performance. In Malaysia, there are different categories of manufacturing industry. There are the different kinds of industry such as textile, petrochemical automotive, plastic, wood based, electronics and many others. As most of accident were occur by the unsafe performances at their workplace, so it's very important that good attitude $\mathrm{s}$ should be possessed by individuals in order to exhibit safety behaviors [7-8].

For this situation, safety culture gives direction to the workers to understanding the importance of working environment with safe workplace. Safety culture organization promote belongingness, trust and participation among the worker through their cohesiveness and membership. They remind each other on the significance of safety and encourage communication through teamwork. In additional safety culture offer them for the guidance of safety practices in the organization and also provides the share values and beliefs that assist workers to realize organizational safety. Furthermore to propagate safety information for launching communication networks and safety activities, it emphasizes on broad participation by employees. It keeps up a fundamental concentrate on the interior authoritative safety standard. In an association with wellbeing safety trends, working 
environment safety has never been traded off with efficiency. Pioneers lead the laborers by showing safety is an incentive to them and to the association. They convince that the working environment is safe for the staff to perform their responsibilities. In this way, workers will have more sureness to do their duties and they can also enhance the productivity. As far as molding individual wellbeing practices, safety culture supports the display of wellbeing consistence and safety interest conduct. It advances wellbeing in the feeling of strengthening and self-belongingness.

Table \# 1 respectively present the total number of accidents and by types of accident in Malaysia during 2012 to 2016. There was significant increase in the total number of accidents reported for all sectors, increase $24.90 \%$ from 2780 in 2012 to 3702 in 2016 . There was also significant increase in the total number death and non-permanent Disability respectively reported for all sectors, increase 20.4\% from 191 in 2012 to 240 in 2016 and increase $28.9 \%$ from 2382 in 2012 to 3348 in 2016 . There was significant decrease in the total number of permanent Disability reported for all sectors, Decrease $43.7 \%$ from 207 in 2012 to 144 in 2016[9-13].

Table 1. Number of Report accident 2012-2016

\begin{tabular}{|c|c|c|c|c|}
\hline Years & $\begin{array}{c}\text { Total Accident } \\
\text { Reported }\end{array}$ & Death & $\begin{array}{c}\text { Permanent } \\
\text { Disability }\end{array}$ & $\begin{array}{c}\text { Non -Permanent } \\
\text { Disability }\end{array}$ \\
\hline 2012 & 2,780 & 191 & 207 & 2,382 \\
\hline 2013 & 2,826 & 185 & 165 & 2,476 \\
\hline 2014 & 2,805 & 204 & 145 & 2,456 \\
\hline 2015 & 3,344 & 213 & 122 & 3,009 \\
\hline 2016 & 3,702 & 240 & 144 & 3,348 \\
\hline
\end{tabular}

Among all sectors, Table \#2 the number of accidents reported for the manufacturing sector has been the highest throughout the period since increase $26.2 \%$ from 1722 in 2012 to 2333 in 2016 . This reflects specialists in the manufacturing area are presented to high accidental dangers. It can be watched that the pattern of accident reports varies from one sector to another sector, reflecting the difference of hazard crosswise over all sectors.

Table 2. Industrial accidents reported by sectors, Malaysia, (2012 to 2016)

\begin{tabular}{|l|c|c|c|c|c|}
\hline Sector & 2012 & 2013 & 2014 & 2015 & 2016 \\
\hline Manufacturing & 1,722 & 1,655 & 1,667 & 2,040 & 2,333 \\
\hline Mining and Quarrying & 42 & 35 & 62 & 39 & 25 \\
\hline Construction & 177 & 164 & 172 & 237 & 233 \\
\hline Agriculture, Forestry, Logging and Fishery & 446 & 535 & 492 & 480 & 471 \\
\hline Utility & 94 & 108 & 70 & 96 & 75 \\
\hline Transport, Storage and Communication & 95 & 93 & 102 & 131 & 130 \\
\hline Wholesale and Retail Trade & 73 & 78 & 83 & 108 & 109 \\
\hline Hotel and Restaurant & 15 & 20 & 57 & 62 & 90 \\
\hline $\begin{array}{l}\text { Financial, Insurance, Real Estate and Business } \\
\text { Services }\end{array}$ & 62 & 71 & 74 & 119 & 126 \\
\hline Public Services and Statutory Bodies & 54 & 67 & 26 & 32 & 110 \\
\hline Grand Total & 2780 & 2826 & 2805 & 3344 & 3702 \\
\hline
\end{tabular}


During 2011 to 2016 Table \# 3, the statistic of occupational accident in Malaysia illustrated that the first highest non-permanent and permanent disabilities were recorded in manufacturing industry (DOSH Malaysia, 2012 to 2016) and second highest Death/Fetal accident were also recorded in manufacturing Industry (DOSH Malaysia, 2011 to 2016).

There is significant increase in the total number of non-permanent Disability in manufacturing industry reported for all sectors and increase from 1535 in 2012 to 2187 in 2016 with an increment of $42.5 \%$. Also there is a significant increment in the total number permanent Disability in manufacturing industry as compare to other sector.

While the total number of permanent Disability in manufacturing industry reported for all sectors having a decrease from 147 in 2012 to 74 in 2016 with a decrement of $49.7 \%$. But an increment in the total number Death in manufacturing industry has been reported with numbers from 40 in 2012 to 72 in 2016 by $80 \%$ increment.

Table 3. Industrial occupational accidents categories (D, PD \& NPD) reported by sectors, Malaysia, (2012 to 2016)

\begin{tabular}{|c|c|c|c|c|c|c|c|c|c|c|c|c|c|c|c|}
\hline \multirow{2}{*}{ 윰 } & \multicolumn{3}{|c|}{ NrON } & \multicolumn{3}{|c|}{ wrON } & \multicolumn{3}{|c|}{ ErON } & \multicolumn{3}{|c|}{ UேーON } & \multicolumn{3}{|c|}{ aron } \\
\hline & $\theta$ & $\theta \forall z$ & $\theta$ ס & $\theta$ & $0 \times z$ & סים & $\theta$ & $00 \%$ & סים & $\theta$ & $00 \%$ & $\theta$ & $\theta$ & $0 \times z$ & $\theta 0$ \\
\hline 息愿备 & ह & v & 昰 & ळ & 呫 & 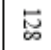 & 克 & 0. & 点 & 点 & $0 \overrightarrow{8}$ & $\mathscr{8}$ & $\vec{N}$ & - & 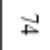 \\
\hline 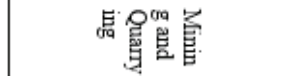 & $\omega$ & 岕 & $\omega$ & $u$ & 岁 & $\circ$ & E & 志 & 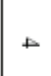 & + & 岕 & $\omega$ & 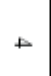 & $\cong$ & $\circ$ \\
\hline 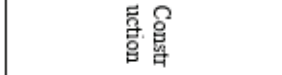 & 9 & 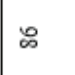 & is & 8. & 心 & i & ה & $\nsubseteq$ & $a$ & $\mathscr{\infty}$ & 岕 & 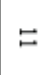 & 8 & : & u \\
\hline 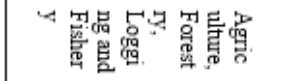 & 岕 & 岕 & నু & 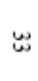 & 㤐 & 平 & 心 & E & 0 & $\breve{\Xi}$ & 专 & 0 & 岕 & 䓌 & 0 \\
\hline पद & $u$ & $\mathscr{\Omega}$ & $\omega$ & $\omega$ & 8 & $r$ & $\circ$ & b & - & $a$ & 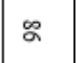 & + & n & 8. & + \\
\hline 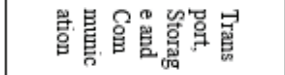 & 心 & ळ & u & $\infty$ & $\stackrel{\infty}{+}$ & $r$ & $\vec{v}$ & 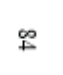 & $\omega$ & N & $\stackrel{9}{9}$ & n & $\varpi$ & $\vec{E}$ & n \\
\hline 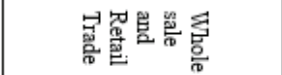 & + & s & $a$ & $u$ & 2 & $\sim$ & $a$ & $\mp$ & $\omega$ & $\omega$ & 胥 & $\omega$ & $\circ$ & 宫 & 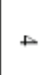 \\
\hline 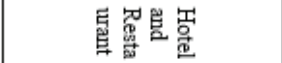 & 0 & 至 & - & $\circ$ & $\vec{b}$ & 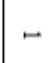 & $\circ$ & ঝ̆ & - & 0 & S & $\circ$ & $\omega$ & 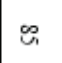 & n \\
\hline 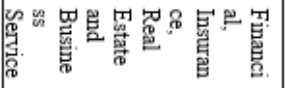 & + & 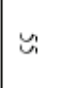 & $\omega$ & $\circ$ & $\ddot{o}$ & $\vdash$ & + & s & $u$ & ⿷ & 㝒 & $\circ$ & Б & 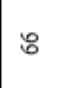 & $\Xi$ \\
\hline 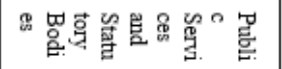 & + & 古 & - & $\circ$ & 9 & $\circ$ & u & "艹 & $r$ & $\circ$ & 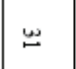 & - & $a$ & s. & $\omega$ \\
\hline 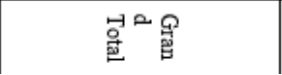 & 웅 & 荵 & 苟 & 品 & 点 & 空 & 莒 & 苔 & 点 & $\stackrel{心}{\omega}$ & 岁 & 志 & 苦 & $\underset{\omega}{\omega}$ & 昰 \\
\hline
\end{tabular}

As per the record from DOSH Table \# 4 show that in last 5-Years, the increment in the fatal accidents by Average 26\%, Permanent Disability by Average $71 \%$ and Non-Permanent Disability by $64 \%$ are investigated only in Manufacturing Industries. 
Table 4. Industrial accidents of Manufacturing sector last five years (2012 to 2016)

\begin{tabular}{|c|c|c|c|c|c|c|c|c|c|}
\hline \multirow{2}{*}{ Year } & \multicolumn{3}{|c|}{ Death (D) } & \multicolumn{3}{c|}{$\begin{array}{c}\text { Permanent } \\
\text { Disability (PD) }\end{array}$} & \multicolumn{3}{c|}{$\begin{array}{c}\text { Non-Permanent } \\
\text { Disability (NPD) }\end{array}$} \\
\cline { 2 - 11 } & Total & MFG & \% & Total & MFG & \% & Total & MFG & \% \\
\hline $\mathbf{2 0 1 2}$ & 191 & 40 & 21 & 207 & 147 & 71 & 2,382 & 1,535 & 64 \\
\hline $\mathbf{2 0 1 3}$ & 185 & 58 & 31 & 165 & 128 & 78 & 2,476 & 1,469 & 59 \\
\hline $\mathbf{2 0 1 4}$ & 204 & 45 & 22 & 145 & 112 & 77 & 2,456 & 1,510 & 61 \\
\hline $\mathbf{2 0 1 5}$ & 213 & 46 & 22 & 122 & 89 & 73 & 3,009 & 1,906 & 63 \\
\hline $\mathbf{2 0 1 6}$ & 240 & 72 & 30 & 114 & 74 & 65 & 3,348 & 2,187 & 65 \\
\hline \multicolumn{3}{|c|}{$\begin{array}{c}\text { Average \% of } \\
\text { 5 Years (D) }\end{array}$} & $25 \%$ & $\begin{array}{c}\text { Average \% } \\
\text { of 5 Years } \\
\text { (PD) }\end{array}$ & $75 \%$ & $\begin{array}{c}\text { Average \% } \\
\text { of 5 Years } \\
\text { (NPD) }\end{array}$ & $64 \%$ \\
\hline
\end{tabular}

In this way, accident and their results keep on being a noteworthy general for public health concern. Moreover, the Occupational Safety and Health Act (OSHA) 1994 expressed that the self-direction idea was declared in view of the essential duty of ensuring safety, wellbeing and welfare of all people at all work environments. In this way, a presentation of safety culture can be viewed as an orderly arrangement towards the foundation of zero accident in the working environment [14].

\section{Occupational disease}

Manufacturing industries in Malaysia give most extreme consumer loyalty ceaselessly experience advancements. These developments in new developing innovation that has prompting greater progression in modern assembling forms with a subsequent increment the field of industrial manufacturing with resulting new growing technology has leading to new type of disease impact on human health [15]. The more up to date sorts of work related diseases, illnesses and injuries are also developing without the labors been realizing that new innovation brings new health issues [16-17].

Depicted occupational health as the progression and safety of the most elevated level of mentally, physical and social prosperity of specialists in all occupations. Manufacturing industries are emphases on the raw materials and that raw material convert into finish product that goods will be fulfil customer satisfaction according to their needs. So diseases occur during the process manufacturing of raw material convert into finish product also generate term as industrial disease. As occupational health and safety focus on two expect Health and safety, health associated free from diseases and safety associated free accident or injury happen during the manufacturing.

Epidemiologic reviews have credited overabundance work related deaths, sicknesses, diseases and injuries due to related manufacturing industry [18].The expanding rate of fatalities because of work related occupational disease and sickness is a reasonable sign that worker are not completely aware of the potential source occupational disease and sickness related with poor health practices in their work related environment [19].Another work related wellbeing estimation for cases with days from work is musculoskeletal disorders (MSDs) [20].

Many of the worker working without health care hazard exiting in their work related area [21]. Industries laborers are likewise disregard of the obligations in term of health care because of the carelessness of employer and administration group. This is the poor work related health practices existing in the Malaysia manufacturing industry.

In 2015, a total of 5960 cases of occupational disease and poisoning have been reported to the Occupational Health Division as compared with 2648 cases reported in the year 2014 
as Table \# 5. This shows an increment of $55.57 \%$ in occupational disease and poisoning. A sum of 4034 cases have been effectively examined for the purpose of carrying out improvements to the workplace in terms of occupational health. An aggregate of 3377 instances of work related diseases that were investigated were of noise-induced hearing loss (NIHL) and the disease is still the most common occupational disease experienced by workers $(83.7 \%)$ as compared with other diseases. This was trailed by work-related musculoskeletal diseases, i.e. a total of 147 cases (4.4\%) and occupational lung diseases, of 91 cases $(2.3 \%)$ were investigated in 2015 as shown in Table. 6 . Diseases caused by physical agents were the least investigated diseases by the Division whereby no cases were investigated in 2015.[22] [23]

Table 5. Statistic of Occupational Poisoning and Diseases from the Year $2012-2015$

\begin{tabular}{|r|c|}
\hline Years & Number of Occupational Diseases Cases \\
\hline 2011 & 1,198 \\
\hline 2012 & 1,792 \\
\hline 2013 & 2,588 \\
\hline 2014 & 2,648 \\
\hline 2015 & 5,960 \\
\hline
\end{tabular}

Table 6. Statistics of Occupational Poisoning and Diseases by Type of Diseases for the Year 2015

\begin{tabular}{|c|c|c|c|c|c|}
\hline $\begin{array}{l}\mathscr{n} \\
\stackrel{\sim}{Z} \\
0\end{array}$ & 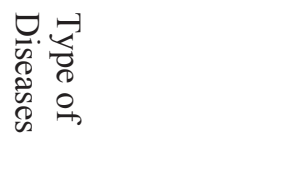 & 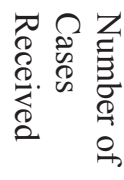 & 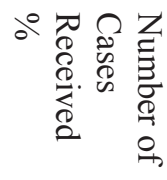 & 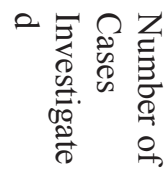 & 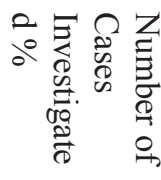 \\
\hline - & 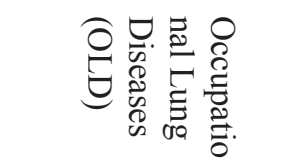 & $\vec{\sim}$ & $N$ & $\bullet$ & $\stackrel{N}{w}$ \\
\hline$N$ & 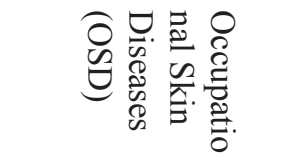 & $\stackrel{t}{a}$ & - & $\mathcal{N}$ & $\stackrel{\circ}{ }$ \\
\hline$\omega$ & 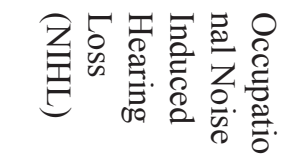 & $\begin{array}{l}u \\
\dot{w} \\
\text { à }\end{array}$ & ๖ & $\stackrel{w}{J}_{J}^{w}$ & $\stackrel{\infty}{\sim}$ \\
\hline$\triangle$ & 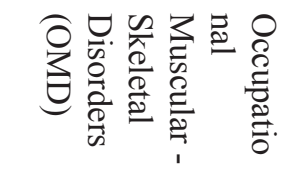 & $\frac{N}{\mathbb{E}}$ & $\triangle$ & \pm & $\stackrel{\vec{A}}{\vec{A}}$ \\
\hline ur & 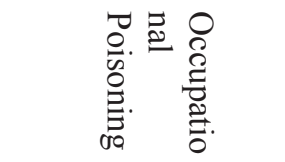 & N & - & $\mathcal{N}$ & $\stackrel{\circ}{ }$ \\
\hline
\end{tabular}




\begin{tabular}{|c|c|c|c|c|c|}
\hline $\begin{array}{l}\mathscr{\sigma} \\
\stackrel{2}{\sigma}\end{array}$ & 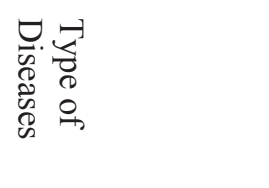 & 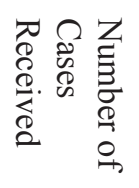 & 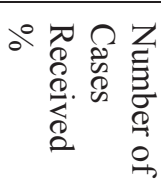 & 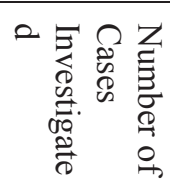 & 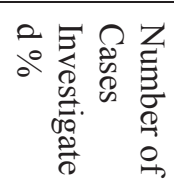 \\
\hline$\sigma$ & 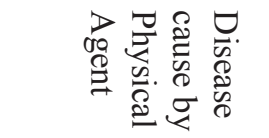 & ur & 0 & 0 & 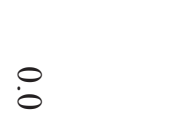 \\
\hline$v$ & 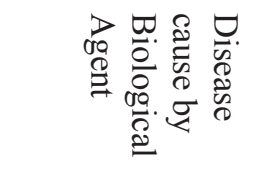 & $\vec{\omega}$ & - & 岕 & $\bar{i}$ \\
\hline$\infty$ & 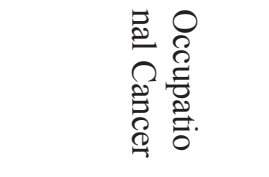 & $\omega$ & 0 & $N$ & $\stackrel{\circ}{0}$ \\
\hline 0 & 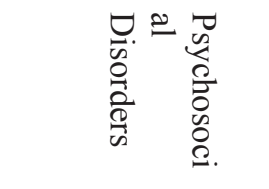 & $N$ & 0 & - & $\stackrel{\circ}{\circ}$ \\
\hline$\sigma$ & 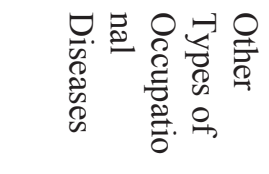 & $\vec{\sigma}$ & 0 & $a$ & $\stackrel{0}{-}$ \\
\hline$\Xi$ & 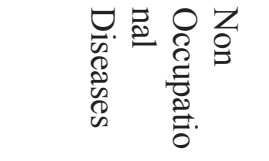 & $\tilde{\sigma}$ & - & $\stackrel{\mathscr{\perp}}{\mathscr{\perp}}$ & $\vec{u}$ \\
\hline \multicolumn{2}{|c|}{ 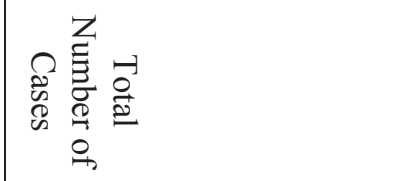 } & \multicolumn{2}{|c|}{$\begin{array}{l}u \\
\text { ŏ }\end{array}$} & \multicolumn{2}{|c|}{ 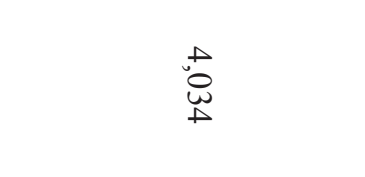 } \\
\hline
\end{tabular}

Investigation of work related diseases and poisoning by sector revealed that the manufacturing sector noted that most number of cases of work-related disease and poisoning in 2015 , a total of 3487 cases $(86.4 \%)$. This was followed by the public service sectors, of 147 cases $(4.4 \%)$ and the agricultural sector, a total of 122 cases $(3.0 \%)$ As shown in table \# 7. The Occupational Health Division also investigated ex-gratia compensation cases for occupational disease confirmation purpose for the government employees and a total of 38 cases have been successfully investigated for the year 2015 as shown in Table \# 8. 
Table 7. Occupational Disease and Poisoning By Sector Dosh 2015

\begin{tabular}{|c|l|c|c|}
\hline Sr.No. & Sector & $\begin{array}{c}\text { No. of } \\
\text { Cass }\end{array}$ & $\%$ \\
\hline 1 & Manufacturing & 3,487 & 86.4 \\
\hline 2 & Mining and Quarrying & 109 & 2.7 \\
\hline 3 & Construction & 5 & 0.1 \\
\hline 4 & Agriculture, Forestry, Logging and Fishery & 122 & 3.0 \\
\hline 5 & Utility & 77 & 1.9 \\
\hline 6 & Transport, Storage and Communication & 17 & 0.4 \\
\hline 7 & Wholesale and Retail Trade & 4 & 0.1 \\
\hline 8 & Hotel and Restaurant & 14 & 0.3 \\
\hline & Financial, Insurance, Real Estate and Business & 50 & 1.2 \\
\hline 9 & Services & 149 & 3.7 \\
\hline 10 & Public Services and Statutory Bodies & & \\
\hline
\end{tabular}

Table 8. Occupational Disease and Poisoning (Ex Gratia) By Type of Diseases DOSH 2015

\begin{tabular}{|l|r|}
\hline Types of Occupational Diseases & No. \\
\hline Occupational Lung Diseases & 22 \\
\hline $\begin{array}{l}\text { Occupational Muscular - Skeletal Disorders } \\
\text { (OMD) }\end{array}$ & 2 \\
\hline Occupational Skin Diseases & 1 \\
\hline Diseases Caused Biological Agents & 3 \\
\hline Other Occupational Diseases & 1 \\
\hline Non Occupational Diseases & 9 \\
\hline
\end{tabular}

A decent national OSH framework is basic for the powerful execution of national strategies and developers to strengthen the avoidance of work related diseases; it should be incorporate [24]:

1. Laws and regulation and, where proper, aggregate understandings joining the counteractive action of work related diseases;

2. Law obedience instruments, including viable OSH investigation frameworks;

3. Participation amongst administration and laborers and their delegates in the usage of OSH measures;

4. Providing of occupational health facilities;

5. Satisfactory components for the accumulation and investigation of information on occupational diseases;

6. Occupational health and Safety information and training;

7. Collaboration between departments of Labour, department of health and social security schemes covering work-related injuries and diseases.

\section{Conclusion}

In conclusion, research on occupational accident in Malaysia is generally lacking and needs to be strengthened. Future research should focus on high-risk industries (manufacturing, construction, agriculture and transportation). Future occupational management systems and the role of a safer design of the environment including equipment and machinery. The 
effectiveness of OSHA should be evaluated and measures to further implement it should be developed. Comparative research into the effectiveness of occupational safety practices in our country with other developed nations will be helpful.

Despite more than 18 years have passed since OSHA was first implemented in Malaysia, there has been no revision done on OSHA. Since Malaysia is a fast growing country since the last three decades, there are certain provisions that may no longer be compatible with current situation. For example, in the manufacturing industries, new machineries with new technologies have been introduced which consequentially requires some of OSHA's provision to be revised.

For government, industry administration and workers an improvement in occupational safety and health is needed. Mishaps at the job environment ought to be kept with the participation from both managers and representatives on top of customary authorization from the legislature. Occupational accidents are avertable and occupational accidents can be omitted through proper safety measures. Compared to disabilities in terms of non-permanent are less likely as compared to permanent disabilities and deaths.

The administration, staffs and DOSH must consolidate strengths and attempt to forestall future occupational accidents by tending to the underlying reason of accidents. To develop a good safety trend at workplace, the rules from government, employer and workers need to combine together.

Malaysia aimed to reduce the occupational accidents, however; the results show by DOSH increase that Occupational Noise Induced Hearing Loss 83.7\%, occupational musculoskeletal diseases, $4.4 \%$ and occupational lung diseases $2.3 \%$. But the as per the record from DOSH that in last 5-Years, the increment in the fatal accidents by Average $26 \%$, Permanent Disability by Average $71 \%$ and Non-Permanent Disability by $64 \%$ are investigated only in Manufacturing Industries. The government must show their high interest on such a vulnerable employees to accomplish the above aim. This step will be helpful for planning to reduce the accidents in workplaces and it will also detect the prevention for the future accidents.

\section{Acknowledgement}

This research work is fully funded by office for research, innovation, commercialization, consultancy management (ORICC), Universiti Tun Hussein Onn Malaysia (UTHM) Parit Raja, Johor under vote number U595.

\section{Reference}

1. Government of Malaysia. Occupational Safety and Health Act (Act 514) 1994

2. Knowledge Management to Promote Occupational Safety and Health at the Malaysian Manufacturing Workplace: Reposed in Occupational Safety and Health Committees? Ummu Kolsome Farouk, Stanley Richardson and Arul Jeganathan Solucis Santhapparaj Multimedia University, Malaysia

3. Soehod, K. (2007). 'Law on Safety and Health in Malaysia,' Unpublished manuscript, Universiti Teknologi Malaysia.

4. Government of Malaysia. Occupational Safety and Health Act (Act 514) 1994.

5. Safety Culture in Malaysian Workplace: An Analysis of Occupational Accidents HuiNee A* Hui-Nee 2014 Health and the Environment Journal, 2014, Vol. 5, No. 3.Workplace Accident in Malaysia: Most Common Causes and Solutions Noorul Huda Zakaria, Norudin Mansor, Zalinawati Abdullah Business and Management Review Vol. 
2(5) pp. $75-88$ July, 2012

ISSN: 2047 - 0398 Available online at http://www.businessjournalz.org/bmr.

6. Factors Contribute to Safety Culture in the Manufacturing Industry in Malaysia, Ong Choon Hee Universiti Utara Malaysia, Sintok, Kedah, Malaysia , DOI: 10.6007/IJARBSS/v4-i4/753 URL: http://dx.doi.org/10.6007/IJARBSS/v4-i4/753 , International Journal of Academic Research in Business and Social Sciences April 2014, Vol. 4, No. 4 ISSN: 2222-6990.

7. Mullen, J. (2004). Investigating factors that influence individual safety behavior at work. Journal of Safety Research, 35, 275-285.

8. Preliminary Study of the Safety Culture in a Manufacturing Industry ,Ezrin Hani Sukadarin , Nurud Suria Suhaimi ,Norhidayah Abdull, Department of Technology Management Faculty of Manufacturing Engineering and Technology Management University Malaysia Pahang 26300, Pahang, Malaysia, International Journal of Humanities and Social Science Vol. 2 No. 4 [Special Issue - February 2012].

9. http://www.dosh.gov.my/index.php/en/archive-statistics/2012-archive-stat/795occupational-accidents-statistics-2012

10. http://www.dosh.gov.my/index.php/en/archive-statistics/2013/843-occupationalaccidents-statistics-by-sector

11. http://www.dosh.gov.my/index.php/en/archive-statistics/2014/1225-occupationalaccidents-statistics-by-sector-2

12. 12http://www.dosh.gov.my/index.php/en/archive-statistics/2015/1713-occupationalaccidents-statistics-by-sector-until-december-2015

13. http://www.dosh.gov.my/index.php/en/archive-statistics/2016/1846-occupationalaccidents-statistics-by-sector-until-december-2016

14. Belanger, P.L. (1981). Health hazard evaluation report. Center for disease control, NIOSH report no. HETA $81-107$

15. David A.G.(2006).Occupational contribution to chronic cough. Journal of occupational medicine and toxicology. Retrieved $27^{\text {th }}$ December, 2012 from www.occup/med.com

16. Eilbert, A. (1996). Occupational health hazards. Retrieved $27^{\text {th }}$ December, 2012 from www.occup/med.com.

17. Wikipedia (2011). Work-related diseases, industries. Retrieved $27^{\text {th }}$ December, 2012 from www.wikibooks.com 